\title{
Presentación del «panfleto contra el todo» de Fernando Savater ${ }^{1}$
}

\section{Encuadre:}

Es el mismo Savater, quien, en otro lugar ${ }^{2}$ habla de un «pensamiento negativo", que ha aparecido en todas las filosofías, a través de todas las épocas, como algo inherente a ellas y también como producto o consecuencia de ellas. "Al hablar de «pensamiento negativo» aludo a cierto discurso atareado en dudar de la absoluta necesidad del texto establecido del mundo, en desacreditar las apologías de lo existente, en hallar fallos en el tejido de la realidad, en llevar las contradicciones de la llamada sabiduría hasta su punto más alto, en desaprender lo que se consideraba mejor aprendido y en otras tareas subsidiarias y de idéntico corte ${ }^{3}$. Así se entiende este pensamiento negativo. Incluso dicho "pensamiento negativo» es «la función primordial y específica de la Filosofía». $Y$ este pensamiento negativo, «tendencia crítica que de un modo $u$ otro aparece en todas las filosofías», no pensemos que es - porque no lo es«una escuela o un sistema». Tan sólo se constata. El sistema o la escuela se hace, se piensa, se prepara, se programa.

Y sigue hablando Savater sorprendiéndonos con otra nueva constatación: «un pensamiento reconciliado». Tal pensamiento reconciliado, que participa de algunas características del pensamiento negativo ha hecho su aparición en la filosofía actual, o más específicamente en la filoṣofía posthegeliana. Es «el

1. Fernando Savater, profesor en la Universidad Autónoma de Madrid, y en la Universidad a Distancia, nació en 1947. Autor representativo en los momentos españoles actuales con obras como La filosofia tachada, Ed. Taurus 1972. La piedad apasionada, Ed. Sígueme, 1977. Ensayo sobre Ciorán, Ed. Taurus. La Infancia recuperada, Ed. Taurus, 1977. Su último libro, Panfleto contra el Todo, Ed. Dopesa, Barcelona, 1978, fue galardonado con el «Premio de Ensayo Mundo, 1978». Activo participante en los Congresos de filosofos jóvenes; colaborador frecuente de la sección «Arte y Pensamiento» de «El País». Fue expulsạdo a su «debido» tiempo de la Universidad. Esta le abrió sus puertas con la llegada de los nuevos tiempos.

2. M. A. Quintanilla, (dirigido por), Diccionario de filosofia contemporánea. Ed. Sígueme. Salamanca 1976, 334-346.

3. M. A. Quintanilla, o.c., 334. 
sistema que ha logrado integrar en su necesaria coordinación incluso los aspectos negativos y contradictorios que todavía perturbaban la ciudad ideal platónica. La realidad halla en el discurso especulativo y sistemático su más completa validación, el difinitivo refrendo de la necesidad y razonabilidad de lo que hay: todo es bueno, porque todo es pensable» ${ }^{4}$. Se distinguen cuatro niveles en este «pensamiento reconciliado»: NIVEL ACADÉMICO: el cual halla su reconciliación en la transmisibilidad de los conocimientos, en su carácter de «datos positivos», de respuesta a un problema. NIVEL RELIGIOSO: la reconciliación se da a nivel de la salvación y de la inmortalidad personal, enfocando la religión como el monoteísmo de Occidente. NIVEL CIENTÍfICO: la reconciliación se da en la utilidad de la transformación que nos proporcionan el conjunto de conocimientos empírico-matemáticos orientados a largo o corto plazo a finalidades técnicas: sería la identificación de "científico», "verdadero» y «útil». Y un último NIVEL SOCIOLÓGICO O REVOLUCIONARIO: hallaría su reconciliación en «todo ese pensamiento destinado a reflexionar sobre las condiciones actuales del estado, los mecanismos del poder, las contradicciones del orden y los medios de conservar, conquistar o suprimir las cimas de la jerarquía» ${ }^{5}$.

A pesar de todo, después de Hegel se han visto manifestaciones de un "pensamiento negativo no reconciliado», o no reconciliado totalmente.

Para Savater «se enfrenta al objetivismo sociológico el gran rechazo subjetivista, que niega tanto las formas establecidas del poder como la oposición tradicional a éste y se rehúsa a interiorizar la sumisión a la jerarquía autoritaria aun como forma de un partido revolucionario; frente al perpetuo aplazamiento de las satisfacciones hasta el día siguiente a la revolución, la subjetividad reclama el paraíso ahora" ${ }^{6}$. De esta forma, en estas categorías, 'aparece ese pensamiento negativo no reconciliado.

Este «Panfleto contra el Todo», quedaría orientado, según el pensamiento de su mismo autor, dentro del NIVEL SOCIOLÓGICO O REVOLUCIONARIO, como un pensamiento «reconciliado» y «negativo» al mismo tiempo; es decir: como un «pensamiento no totalmente reconciliado».

\section{El Todo como problema concreto en el Todo político; y la política como problema totalizante}

«Todo va bien. Todo va mal. En cualquier caso, todo va: es el Todo lo único que va». Dice Hegel: «Sólo piensa quien piensa desde el Todo y hacia el Todo». Pero ¿y qué es este Todo? Pues sabemos algo de él: que «quizá sea el Todo quien nos piensa», que «suyo es el poder», y que «el Todo es lo verdade-
4: Ibid., 335.
5. Ibid., 335-336.
6. Ibid., 337. 
ro, que sólo el Todo puede ser verdad, según dictamen del gran administrador del Todo, Hegel. Por eso nos hiere y a la vez, secretamente, nos euforiza la proclamación con que se subleva el hegeliano Adorno: «El Todo es lo falso». De aquí partimos y aquí tenemos que volver» ${ }^{7}$.

«El Todo es plural y uno: necesita la pluralidad para funcionar, la unidad para eternizar su orden ${ }^{8}$. Este sería el Todo Total y más abstracto, planteado como problema único y que Savater enseguida reduce: «Centrémonos ahora en el terreno político, que es el que este planfleto particularmente nos interesa»; por eso «el lugar donde debe efectuarse la denuncia del Todo es el lugar del Estado, por eso este Panfleto tiene que incurrir directamente en lo político" ${ }^{9}$. Y será «una política que vaya tanto contra el Capital como contra el Pueblo, que no favorezca a la Sociedad pero tampoco halague al Individuo» ${ }^{10}$. ¿Se contradice? Veamos el capítulo siguiente: «Pues, siendo éste un panfleto contra el Todo, pudiera pensarse que lo que propugna es una defensa del individualismo, considerando a éste último como el opuesto natural del primero. El punto de vista que sostengo es aproximadamente contrario: a saber, que el individuo es la más firme y sólida herramienta teórica y política del Todo, que nace con éste y para servir a éste, que incluso en sus desviaciones anticolectivas - si sigue conservando su identidad individual - le rinde servicio y pleitesía» ${ }^{11}$. No nos desanimenos. O mejor, reflexionemos otros instantes antes de alarmarnos en profundidad. Porque «este Todo -en palabras de Bertrans du Jouvenel- no es un hecho, por más cuidado que se ponga en romper todas las tradiciones y todas las formaciones particulares existentes. Es una ficción que se pretende tanto más ardientemente acreditar cuanto que constituye el título nobilitador del poder. Creo que éste es el punto esencial de todo este panfleto, el secreto a voces de la ideología política moderna - tanto derechista como izquierdista» ${ }^{12}$.

El Poder y el Todo están interrelacionados: «Es el Poder el que crea un Todo social - ese es precisamente su poder - y al mismo tiempo a ese Todo le es imprescindible a nivel simbólico como justificación racional de su dominio» ${ }^{13}$. No es ni más ni menos que lo que afirma Agustín García Calvo, cuando habla del Estado como mentira y realidad: «...antes de mostrar por los medios que pueda la realidad del Estado, deseo pararme a considerar la relación entre ambas cosas: mentira y realidad. Que es que domina más bien, también entre la gente, pero sobre todo entre los políticos, la idea de que la práctica es la práctica y las ideas las ideas: es contra ella contra la que aquí me empeño en

7. F. Savater, Panfleto contra el Todo, Ed. Dopesa. Barcelona 1978, 15.

8. F. Savater, o.c., 16.

9. Ibid., 20.

10. Ibid., 20.

11. Ibid., 59.

12. Ibid., 28.

13. Ibid., 29. 
sugerir cómo las ideas son el fundamento mismo del Poder: no hay poder sin necesidad de justificación, y por tanto de como dicen los políticos, ideología, tanto más eficaz y poderosa cuanto más abstracta y metafísica sea y por tanto más difícil de denunciar la idea porque es ya lo que todo el mundo sabe. De manera que bien puede decirse que la justificación o ideas dominantes, esto es, la mentira, son el fundamento de la realidad política (que es la humana) y que son su fuerza. Son, por otra parte, su debilidad: porque la necesidad de justificación que el Señor - el Todo- padece y que le hace desarrollar en forma de ideas es lo que tal vez permita alguna esperanza de que hablando (de las ideas, es decir, contra las ideas) pueda estarse haciendo algo práctico y eficaz contra el Señor o contra el Poder -o contra el Todo-; esperanza, desde luego, no asegurada por nadie ni por nada» ${ }^{14}$. Esta extensa cita ha merecido la pena, porque resulta que «no sólo el capital es Poder sino también el Poder es Capital y la fusión de ambos aspira a la administracción total, al control de Todo» ${ }^{15}$. En resumen: «El Todo es un delirio paranoico ascendido a teoría lógico-política»" ${ }^{16}$.

\section{La Alternativa del Todo o la alternativa de la Alternativa:}

¿Qué pensaríamos, desde el punto de vista humanista, no ya evolucionista, ni libertario, de aquellos que en una guerra, bien teórica o bien práctica, «vencen pero terminan por aprender a convencer y, si no éstos, al menos sus retoños ya se van preparando una ideología de recambio, una alternativa teórica que les perpetuará en el poder con la tibia garantía de la bendición progresista»? ${ }^{17} \mathrm{Y}$ ¿qué pensaríamos de un rey que al ser elegido dijera a sus súbditos: Señores, hemos de revisar a fondo y reformar nuestro pensamiento, leyes, institutciones, trabajos, etc. Y al poco tiempo de darles más libertad, más pluralidad, de multiplicarles los caminos, de multiplicarles los horizontes a sus súbditos -o por lo menos de hacerles creer que ahora tienen más caminos, más libertad, más horizontes-, paralelamente les multiplicara su policía estatal de carreteras, su policía estatal de pensamiento, su policía estatal de libertades? Pero no nos entretengamos en decir verdades ociosamente y vayamos al tema.

Savater no da tiempo a prevenirnos: «No hay «alternativa de poder» que no venga sencillamente a confirmar que no existe más alternativa que el Poder, lo mismo que el Todo de cada Individuo refleja y refuerza ese extraño individuo Total que es la organización del Poder separado» ${ }^{18}$. «Porque - nos había dicho antes - nada contribuye tan eficazmente al reforzamiento de la

14. Garcta Calvo, Qué es el Estado. Ed. La Gaya Ciencia. Barcelona 1977, 15-16.

15. F. SAVATER, O.c., 25 .

16. F. Savater, o.c., 20.

17. F. SAvater, La Piedad Apasionada. Ed. Sígueme. Salamanca 1977, 86.

18. F. SAvater, Panfleto..., 59. 
sociedad totalitaria como las falsas soluciones que ella misma alienta desde dentro de sus propios planteamientos y acotando sus mismos ideales, las «alternativas» que procura para luego mejor aplastarlas o convertirlas en su opuesto ante el desconcierto más y más desarmado de las almas rebeldes»" ${ }^{19}$. Porque, como muy ciertamente dice en otro lugar, «les obsesiona - a los del Poder y su Todo, o al Todo y su Poder - el monopolio de lo subversivo: no puede haber pensamiento revolucionario fuera del que acepta sus categorías $y$ sus tics verbales» ${ }^{20}$.

Esto es evidente. Por la sencilla razón de que «los medios no son neutros», por la sencilla razón de que «es una falacia (...), el pensar que las armas del Enemigo - del Todo- (que está necesariamente inscrito Él mismo en la forma de sus armas) pueden usarse contra el Enemigo - contra el Todo-》 ${ }^{21}$, que nos dice Agustín G. Calvo. Pudiera caber la posibilidad de ir contra el Todo sin su colaboración: lo que, no obstante, «como se ha visto sobradamente, querer liberarlo Todo es una forma más de querer controlarlo Todo" ${ }^{22}$. O, en todo caso, se podría cambiar el Todo, «pero no contra el Todo». Esto mismo expresado bajo el esquema y problema a la vez, de las clases y su dialéctica sería que: "Cuando la clase se realice como tal, suprimiéndose, cuando tome el control del Todo, tanto en lo que afecta a los proletarios como al resto de los grupos sociales -éstos deberán seguir por lo que se ve, subordinados-, lo que se vivía como cadena se convertirá en libre asociación» ${ }^{23}$, realidad ésta dada, pero por lo mismo, en su existencia se da una falacia: esa falacia que Savater subdivide, en el tercer capítulo, en varias, tales como: la falacia del Todo, la falacia del individuo, la falacia del bien común, la falacia de la historia, etc.

Es decir, no basta sublevarse contra los «ahora dominantes», sino contra la dialéctica histórica misma, contra la vocación centralizadora del poder» ${ }^{24}$. Y que sería lo que intuyó Schopenhauer: «Uno son el torturador y el torturado. El torturador se equivoca, porque cree no participar en el sufrimiento; el torturador se equivoca, porque cree no participar en la culpa» ${ }^{25}$. Lo que pasa es que ahora el torturador será el torturado y el torturado hará de torturador. Con la temporal diferencia de que los que cumplen el papel de torturadores o de expresiones o de defensores-creadores del Todo, prepararán «la gran coartada del Todo que es la justicia junto con la seguridad», de tal forma que «crece la demanda de seguridad - con su consiguiente disminución de libertadporque el peso del Todo fomenta la debilidad de sus partes, las acostumbra a

19. F. SAVATER, O.c., 59.

20. F. Savater, La Piedad Apasionada, 87.

21. A. Garcia Calvo, Qué es el Estado, 69.

22. F. SAVATER, Panfleto... 67.

23. Ibid., 88 .

24. Ibid., 96.

25. SChopenhauer, Citado F. Savater en el Panfleto, 109. 
no gozar de otra fuerza que la que él reparte» ${ }^{26}$. A la vez los que cumplen el papel de torturados «no serán libres porque no desean realmente la libertad». Porque «Solo la libertad - dice La Boetie, citado por Savater - los hombres la desdeñan, únicamente a lo que me parece, porque si la deseasen la tendrían: como se rehusase a hacer esa preciosa conquista porque es demasiado fácil» ${ }^{27}$. En otro libro suyo, ya citado, habla acerca de esto genialmente: «Se ha dicho: las ideas que dominan al mundo son las ideas de los que dominan el mundo. Puede añadirse: lo importante no es cambiar de ideas y de dominadores, sino procurarse ideas no dominantes - no torturadoras-, ideas desligadas de la vocación de dominar» ${ }^{28}$.

Pensémoslo: o creemos en el Todo y su alternativa, o creemos en nosotros y nuestra alternativa que andamos buscando; o creemos en la «falacia» o creemos en «nuestra búsqueda». «El Todo, más cuando se encarna actúa en su forma más horriblemente real de poder-ideología es «la administración teórica de la muerte; de la administración práctica se encargarán los de siempre»" ${ }^{29}$.

\section{A pesar del Todo y del Todo con sus alternativas, la creencia y la crítica como salida:}

Como dice Marcel Gauchet traído aquí por Savater: «Cuando el Poder se apodera de la ley, se pretende la ley, ya no hay ley (...). Un Poder que, por su pretensión de saber, ya no indica algo más allá de él, un poder que rechaza el que haya alguna cosa fuera de sí mismo, disuelve literalmente el lazo social con la dimensión simbólica del espacio colectivo» ${ }^{30}$. Porque «la exigencia de un Todo social cada vez más abstracto, desterritorializado, cosificado, capitalista en suma y la petición de un Estado que procure cada vez más servicios, que sea cada vez más providencia y juez, que substituya ventajosainente al viejo Dios perdido de la trascendencia, éste es el verdadero rostro del individualismo moderno, posterior a, e inventado por, la revolución francesa» ${ }^{31}$. Puesto que ¿quién no ha sentido alguna vez en propia carne que «cuando la ley se desenraíza de la trascendencia religiosa o legendaria y se fija en la claridad manipulable, revocable, de la razón o en la decisión imperiosa del tirano, ya no conoce límites ni hay frente a sus exigencias resguardo alguno?» ${ }^{32}$.

Según esto, hablemos de alguna salida, aparte por supuesto, de que cada cual ha de crear su propia salida, cada cual ha de salirse o asentarse. Cada cual

\footnotetext{
26. F. Savater, o.c., 43.

27. F. SAVATER, o.c., 37-38.

28. F. Savater, La Piedad Apasionada 85.

29. F. SAVATER, La Piedad..., 87.

30. F. Savater, Panfleto..., 82.

31. Ibid., 66.

32. Ibid., 78.
} 
ha de creer-crear o no creer-crear, pero en ambos casos buscar. Es un hecho que a quien no busca, ya de una forma u otra, le busca el Todo; y ya lo creo que lo encuentra.

Primera posible salida: «Pero en modo alguno se crea que me parece lamentable el proceso por el que la ley trascendente de lo social como Todo se ha interiorizado en el período racional y convertido arbitrariamente en Poder. No, porque esta transición, además de dar paso al totalitarismo, permite también, por primera vez, realizar una crítica en profundidad de la función misma de la ley del Todo. La situación en que el Todo se garantizaba desde una trascendencia mítica es -felizmente irrecuperable; nuestra posición actual es particularmente violenta y peligrosa, pero abierta también a una revocación antes inimaginable» ${ }^{33}$. La crítica. Es una posible salida - en principio, como todas las salidas-. Pero no sólo la crítica, sino el simple hablar, «hablar de». «Porque es que si hablas de una cosa, hablas contra ella: sólo se habla de aquello contra lo que se habla: hablar de una idea - quiéralo o no lo quiera el que está hablando- es ponerla en tela de juicio y por tanto hacerla peligrosa de algún modo como idea» ${ }^{34}$. Pero además, porque si no criticamos, si no hablamos, nunca podremos llamar la atención de otros posibles rebeldes que comulgen con nuestra causa o nuestra fe o nuestro ateísmo, y que nacen, crecen y mueren a nuestro lado. Y si no «rebeldes», sí desertores o «simplementes desencantados».

Segunda posible salida: «La razón humana reducida a sus fuerzas individuales es perfectamente nula, no solamente para la creación, sino también para la conservación de toda asociación religiosa o política, porque no produce más que disputas y el hombre, para conducirse, no necesita problemas, sino creencias» ${ }^{35}$. Más "humano» si se quiere, diríamos que se necesitan "pasiones». El hombre necesita hundirse, antes que expansionarse, antes que abarcar, antes que centrarse, o que antes que unificarse; o, mejor, antes que intentar unificarse o centrarse. Dice Kierkegaard: «Cuando un hombre emprende el camino, penoso en un sentido, del héroe trágico, muchos deben estar en condición de aconsejarle; pero a quien sigue la estrecha senda de la fe nadie puede ayudarlo, nadie puede comprenderle — «nadie puede comprenderle»-. La fe es un milagro: sin embargo nadie está excluido; porque aquello en que toda vida humana halla unidad es la pasión y la fe es una pasión» ${ }^{36}$. Pero la fe, ella misma, ayuda, porque ella nos devuelve a nosotros mismos. De ahí que un buen principio - del cuál no se deduce un mejor fin,

33. Ibid., 83.

34. A. Garcia Calvo, o.c., 8.

35. F. SAVATER, o.c., 105. 
ha de creer-crear o no creer-crear, pero en ambos casos buscar. Es un hecho que a quien no busca, ya de una forma u otra, le busca el Todo; y ya lo creo que lo encuentra.

Primera posible salida: «Pero en modo alguno se crea que me parece lamentable el proceso por el que la ley trascendente de lo social como Todo se ha interiorizado en el período racional y convertido arbitrariamente en Poder. No, porque esta transición, además de dar paso al totalitarismo, permite también, por primera vez, realizar una crítica en profundidad de la función misma de la ley del Todo. La situación en que el Todo se garantizaba desde una trascendencia mítica es -felizmente irrecuperable; nuestra posición actual es particularmente violenta y peligrosa, pero abierta también a una revocación antes inimaginable» ${ }^{33}$. La crítica. Es una posible salida - en principio, como todas las salidas-. Pero no sólo la crítica, sino el simple hablar, «hablar de». «Porque es que si hablas de una cosa, hablas contra ella: sólo se habla de aquello contra lo que se habla: hablar de una idea - quiéralo o no lo quiera el que está hablando- es ponerla en tela de juicio y por tanto hacerla peligrosa de algún modo como idea» ${ }^{34}$. Pero además, porque si no criticamos, si no hablamos, nunca podremos llamar la atención de otros posibles rebeldes que comulgen con nuestra causa o nuestra fe o nuestro ateísmo, y que nacen, crecen y mueren a nuestro lado. Y si no «rebeldes», sí desertores o «simplementes desencantados».

Segunda posible salida: «La razón humana reducida a sus fuerzas individuales es perfectamente nula, no solamente para la creación, sino también para la conservación de toda asociación religiosa o política, porque no produce más que disputas y el hombre, para conducirse, no necesita problemas, sino creencias» ${ }^{35}$. Más "humano» si se quiere, diríamos que se necesitan "pasiones». El hombre necesita hundirse, antes que expansionarse, antes que abarcar, antes que centrarse, o que antes que unificarse; o, mejor, antes que intentar unificarse o centrarse. Dice Kierkegaard: «Cuando un hombre emprende el camino, penoso en un sentido, del héroe trágico, muchos deben estar en condición de aconsejarle; pero a quien sigue la estrecha senda de la fe nadie puede ayudarlo, nadie puede comprenderle — «nadie puede comprenderle»-. La fe es un milagro: sin embargo nadie está excluido; porque aquello en que toda vida humana halla unidad es la pasión y la fe es una pasión» ${ }^{36}$. Pero la fe, ella misma, ayuda, porque ella nos devuelve a nosotros mismos. De ahí que un buen principio - del cuál no se deduce un mejor fin,

33. Ibid., 83.

34. A. Garcia Calvo, o.c., 8.

35. F. SAVATER, o.c., 105. 